DOI: http://dx.doi.org/10.18764/2358-4319.v10n2p147-164

\title{
A leitura como prática de (re)socialização no Sistema Penitenciário Nacional
}

\author{
Marcio José de Lima Winchuar ${ }^{1}$ \\ Diego Paiva Bahls ${ }^{2}$
}

\section{RESUMO}

Este trabalho tem como objetivo realizar um levantamento de pesquisas e de políticas que envolvem a leitura no sistema penitenciário nacional, mapeando dissertações e teses de programas de pós-graduação, que tiveram como tema projetos de leitura no cárcere nos últimos dez anos. Para isso, realizamos uma pesquisa no banco de dissertações e teses do Portal da Capes e na Biblioteca Digital Brasileira de Teses e Dissertações. A partir do levantamento de dados, identificamos que trabalhos que envolvem a educação no sistema prisional ainda são poucos, principalmente, relacionados a práticas de leitura. Essa situação pode ser agravada, sobretudo, pela pseudoefetivação de políticas que regem esses contextos.

Palavras-chave: Leitura. Sistema Prisional. Humanização.

\section{Reading as a practice of reintegration in the National Pententiary System}

\section{ABSTRACT}

The objective of this study is to carry out a survey of research and policies that involve reading in the national penitentiary system, mapping of dissertations and postgraduate theses, which have had the subject of reading projects in the last ten years. For this, we conducted a research in the thesis bank of the Cover Portal and the

1 Mestre em Letras. Doutorando em Educação. Professor colaborador na Universidade Estadual do Centro-Oeste do Paraná - UNICENTRO. Responsável pelo projeto de pesquisa especial (PQE) "Remição pela Leitura: uma análise da lei paranaense no 17.329 de 8 de outubro de 2012", vinculado ao departamento de Pedagogia, da Unicentro-PR. E-mail: E-mail:mwinchuar@gmail.com

2 Graduando do Curso de Pedagogia pela Universidade Estadual do Centro-Oeste e de Licenciatura em Artes Visuais pelo Centro Universitário Internacional - UNINTER. E-mail: diegobahls09@gmail.com 
Brazilian Digital Library of Theses and Dissertations. From the data collection, we identified that work involving education in the prison system is still scarce, mainly, related to reading practices. This situation can be aggravated, above all, by the false effectiveness of policies that govern these contexts.

Keywords: Reading. Prison System. Humanization;

\section{La lectura como práctica de (re)socialización en el Sistema Penitenciario Nacional}

\section{RESUMEN}

Este trabajo tiene como objetivo realizar un levantamiento de investigaciones y de políticas que involucran la lectura en el sistema penitenciario nacional, mapeando disertaciones y tesis de programas de postgrado, que tuvieron como tema proyectos de lectura en la cárcel en los últimos diez años. Para esto, realizamos una investigación en el banco de disertaciones y tesis del Portal da Capes y en la Biblioteca Digital Brasileña de Tesis y Disertaciones. A partir del levantamiento de datos, identificamos que trabajos que involucran la educación en el sistema penitenciario aún son pocos, principalmente, relacionados a prácticas de lectura. Esa situación puede agravarse, sobretodo, por la pseudoefectivación de políticas que rigen esos contextos.

Palabras clave: Lectura. Sistema Penitencioario. Humanización.

\section{Considerações iniciais}

Este texto busca identificar trabalhos que envolvem a leitura no sistema penitenciário nacional, mapeando dissertações e teses de programas de pós-graduação, que tiveram como tema projetos de leitura no sistema penitenciário brasileiro nos últimos dez anos.

Ao considerarmos os altos índices desfavoráveis à prática de leitura no sistema penitenciário nacional (BRASIL, 2009), destacamos a necessidade de pesquisas relacionadas às temáticas que tratem a leitura nesse cenário, tendo em vista o grande número de sujeitos que vive à margem de uma "sociedade letrada". Consideramos que o texto pode influenciar o comportamento do leitor, modificar suas atitudes e torná-lo um sujeito crítico diante da sociedade. 
Nessa conjuntura, tomamos o texto enquanto um mecanismo que "[...] em vez de afiançar valores dominantes pode, por meio da leitura, legitimar novos valores" (JOUVE, 2002, p. 125). Nesse sentido, o texto, por meio de práticas de leitura não trata de transmitir verdades, informações, normas, mas sim de criar novas referências. São essas referências que tornam essas práticas indispensáveis no ambiente penitenciário, pois podem suscitar nos leitores novas formas de ver o mundo e o que os cerca.

Ao encontro do exposto, Candido (1989) menciona que uma sociedade justa pressupõe o respeito dos direitos humanos e a fruição da arte e da literatura em todas as modalidades e em todos os níveis é um direito inalienável. Assim como todo sujeito tem direito saúde, esporte, lazer, tem direito ao acesso à cultura educacional e, nessa esfera, à literatura que o humaniza. Isso a todos os cidadãos, independentemente de cor, raça, credo, situação social, suspenso ou não de seu direito de ir e vir.

Assim, este trabalho justifica-se por realizar um levantamento de pesquisas e projetos que envolvem a leitura no sistema penitenciário na última década, a fim de verificar se efetivamente o sistema educacional na prisão possibilita ao sujeito apenado práticas significativas de leitura e um novo olhar ao mundo, tanto de dentro como de fora da prisão, bem como fortalecer estudos que versam sobre esta temática no cenário nacional.

Neste primeiro momento, este trabalho classifica-se, metodologicamente, como qualitativo, de cunho bibliográfico e documental. Na tentativa de mapear trabalhos na área, realizamos uma pesquisa no banco de dissertações e teses do Portal da Capes3 e o site da Biblioteca Digital Brasileira de Teses e Dissertações (BDBTD)4, a fim identificar pesquisas e trazer à tona as problemáticas analisadas, como também as possíveis lacunas encontradas nesses trabalhos5.

Entendemos como de extrema relevância trabalhos que resgatam e discutam a educação no sistema penitenciário, principalmente através da leitura, uma vez é preciso buscar meios de "garantir" o real

3 Disponível em: http://capesdw.capes.gov.br/

4 Disponível em: http://bdtd.ibict.br/vufind/

5 A partir do direcionamento do site para os repositórios de Universidades foi possível encontrar outros trabalhos que ainda não estão disponibilizados na base de busca.

Revista Educação e Emancipação, São Luís, v. 10, n. 2, maio/ago. 2017 
acesso educacional a sujeitos em situação carcerária, posto que, para Barros e Jordão (2011, p. 4), "a prisão é uma instituição política. Sua função social, após a formação do Estado liberal é de recuperação dos indivíduos, devendo buscar sua ressocialização".

Assim, esse artigo divide-se da seguinte forma: primeiramente apresentamos nosso objetivo e metodologia, conforme exposto acima. Em seguida, apontamos o lugar da leitura literária no sistema penitenciário, a partir de trabalhos desenvolvidos por pesquisadores de universidades de renome no âmbito nacional. Posteriormente, discutimos políticas de leitura na penitenciária, a partir da Lei de Remição Penal n. 17.329/2012 para, por fim, trazermos efeitos de conclusão deste texto.

\section{A leitura literária no sistema penitenciário: algumas discussões}

O ensino de leitura no sistema prisional brasileiro vem recebendo destaque nos últimos anos, a partir de pesquisas que buscam entender o funcionamento e o resultado de práticas que envolvem a leitura nas prisões estadual e federal. Para a realização do estado da arte, utilizamos como palavras chaves os termos: leitura literária, sistema prisional, políticas de leitura e educação de jovens e adultos.

Encontramos dissertações e teses ligadas a programas de pós-graduação em Educação e Letras, de universidades de renome no cenário nacional, das quais destacamos: Universidade Estadual de Maringá (UEM); Universidade Federal de Goiás (UFG); Pontifícia Universidade Católica de Minas (PUC-MINAS); Universidade Federal do Rio Grande do Sul (UFRGS); Universidade de Brasília (UNB) e Universidade Federal de Pernambuco (UFPE). Enfatizamos que, por mais que haja um destaque acerca da temática, poucos trabalhos foram desenvolvidos no tocante à leitura em sistemas prisionais, sobretudo, no âmbito das políticas de leitura.

Para melhor demonstrar as temáticas abordadas nas pesquisas encontradas, organizamos, primeiramente, um quadro demonstrativo, evidenciando a temática e as discussões atuais sobre o ensino de leitura no sistema prisional brasileiro, conforme segue: 
Quadro 1: Temas das pesquisas que abordam práticas de leitura no sistema prisional.

\begin{tabular}{|l|c|c|c|}
\hline $\begin{array}{l}\text { Descrição das temáticas referentes à } \\
\text { leitura no sistema prisional }\end{array}$ & Dissertação & Tese & Total \\
\hline $\begin{array}{l}\text { O acesso à leitura literária no Sistema } \\
\text { Prisional Paranaense }\end{array}$ & 1 & 0 & 1 \\
\hline $\begin{array}{l}\text { A contribuição da leitura literária para a (re) } \\
\text { inclusão de sujeitos privados de liberdade }\end{array}$ & 2 & 0 & 2 \\
\hline $\begin{array}{l}\text { Resgate da identidade de sujeitos em } \\
\text { privação de liberdade, a partir de práticas de } \\
\text { leitura e escrita }\end{array}$ & 4 & 0 & 4 \\
\hline $\begin{array}{l}\text { O perfil do leitor em situação de privação de } \\
\text { liberdade }\end{array}$ & 1 & 0 & 1 \\
\hline $\begin{array}{l}\text { Eventos de letramento ocorridos no interior } \\
\text { da penitenciária: práticas de oralidade, } \\
\text { leitura e escrita }\end{array}$ & 1 & 1 & 2 \\
\hline
\end{tabular}

Fonte: Dados do autor (2016).

O critério utilizado na seleção das teses e dissertações se deu por meio da leitura dos resumos selecionados e analisados, os quais evidenciaram o trabalho com a leitura no sistema prisional brasileiro. Destacamos que não foram encontrados trabalhos que discutam, especificadamente, as políticas de leitura nesse sistema, entretanto, alguns autores (SILVA NETO, 2009), (RIBEIRO, 2012) já evidenciam a necessidade desses estudos.

O maior número de pesquisas é vinculado ao programa de pós-graduação em Letras da Universidade Estadual de Maringá, a partir do projeto "Literatura, Leitura e Escrita: a ressignificação da identidade de indivíduos em situação de exclusão social" ${ }^{\prime \prime}$. Este projeto surgiu de outro projeto denominado "Monteiro Lobato: reconhecendo leitores" desenvolvido como atividade de pós-doutorado (PUC-RS) na Penitenciária Estadual de Maringá, pela professora Dra. Alice Áurea Penteado Martha, sob a orientação da professora Dra. Regina Zilberman.

Ambos projetos frutificaram diversas publicações acerca da temática, incluindo artigos científicos e capítulos de livros. Além disso, é

6 O projeto foi iniciado em 2005 e finalizado em 2008, na Penitenciária Estadual de Maringá (PEM), sob a coordenação das professoras doutoras Alice Áurea Penteado Martha e Marilurdes Zanini, com a participação de graduandos e pós-graduandos em Letras da Universidade. Nesse projeto foram propostas oficinas a presidiários da Penitenciária Estadual de Maringá, tratando a Leitura e Escrita com textos literários referentes às três fases da vida humana: Infância, Juventude e Velhice (VALARINI, 2009). 
tema de investigação de dissertações de mestrado, oriundas dos projetos em questão, das quais destacamos Oliveira (2007), Cruz (2008), Fernandes (2009) e Valarini (2009).

Para Martha (2006), o estudo da leitura na penitenciária resulta do questionamento acerca da importância e a função da leitura para sujeitos que se encontram em situação de exclusão social e/ou privação de liberdade. Assim,

[...] ao enfocar um grupo de leitores diferenciados, no caso presidiários, procuramos considerar a situação precária desses sujeitos e suas leituras, observando especialmente, se pelo fato de o indivíduo viver em situação de exílio na sociedade, por diferentes motivos e formas, a leitura pode vir a ser um dos fatores de resistência ao processo de exclusão e de construção de seu direito de cidadania (MARTHA, 2006, p.187).

Nessa linha de pensamento, Oliveira (2004) problematiza a necessidade de estudos que versam a temática leitura literária no sistema prisional, tendo como objetivo central observar se os detentos da $\mathrm{Pe}$ nitenciária Estadual de Maringá (PEM-PR) possuem acesso à leitura e de que maneira isso ocorre. A pesquisa destaca a presença de "leitores ávidos por novas leituras, leitores dispostos a entrar em contato com novos autores, novos textos e novas perspectivas de vida. Leitores em potencial, que vivem em situação inusitada" (OLIVEIRA, 2004, p. 133), entretanto, foi constatada uma certa deficiência na formação dos professores que atuam na penitenciária e inadequação do material que chega ao presídio, como, por exemplo, o distanciamento da realidade vivenciada.

Na mesma linha de pensamento, Oliveira (2007) analisa em que medida a leitura de obras literárias pelos detentos da Penitenciária Estadual de Maringá pode contribuir para a (re)inclusão desses indivíduos na sociedade civil. Oliveira (2007) comunga da perspectiva da leitura sociológica e da estética da recepção e discute a relação entre obras canônicas e não canônicas, a partir da identificação, por meio de questionamentos prévios, da grande aceitabilidade das obras de Paulo Coelho.

Nessa linha de análise, Cruz (2008) propõe um trabalho de escrita e produção de textos, a fim de analisar os textos produzidos por sujeitos em condição de exclusão social e verificar a contribuição que a 
leitura e a escrita podem oferecer a estes sujeitos. As práticas de leitura e escrita se deram por meio de oficinas oferecidas pelo projeto "Literatura, Leitura e Escrita: a ressignificação da identidade de indivíduos em situação de exclusão social" desenvolvido pela Universidade Estadual de Maringá.

O desenvolvimento do trabalho não se dá, explicitamente, a partir de políticas que envolvem o sistema prisional, pois a ênfase do autor é discutir de forma teórico-prática o papel da leitura e escrita na (re)significação da identidade de sujeitos apenados na PEM. Para Cruz (2008) o trabalho com oficinas de leitura e produção textual contribui para a formação de sujeitos, tanto no sentido de ampliar e (re)significar seu conhecimento de mundo, quanto no sentido de transformar sua postura frente a leitura e a escrita. As práticas de leitura e escrita colaboram no resgate de identidade e autoestima de sujeitos apenados, tornando-os sujeitos ativos, que interagem com o texto e com o outro.

Em consonância com o que vem sendo discutido, Fernandes (2009) verifica de que maneira sujeitos que vivem em reclusão realizam a leitura do texto literário e como o trabalho com a literatura, nesse contexto, contribui para a reflexão, a crítica e o resgate da identidade de sujeitos privados de liberdade.

É possível percebermos, por meio dos dados obtidos na análise dos questionários aplicados aos detentos da Penitenciária Estadual de Maringá e das produções textuais, que a leitura literária permite às pessoas se (re)encontrar como cidadãs, já que, por meio dela, ganham voz e passam a ser ativas na sociedade. Além disso, a leitura na penitenciária contribui para a formação de sujeitos críticos e letrados, que passam a olhar de forma diferenciada a sociedade em que estão inseridos (FERNANDES, 2009).

Valarini (2009) analisa a recepção e a produção de textos de indivíduos marcados pela exclusão social, no caso em tela, os detentos da PEM-PR. A autora apresenta os resultados obtidos na análise dos diários escritos pelos detentos em suas produções textuais. Além disso, fundamentado na teoria da Estética da Recepção e da Sociologia da Leitura, são analisados pela autora o perfil socioeconômico e cultural dos sujeitos envolvidos no projeto.

A pesquisa permite identificar que as oficinas de leitura e escrita contribuem na melhora da recepção e interpretação do texto literário por parte dos apenados envolvidos, entretanto, não ultrapassaram a 
etapa da leitura primária. Apesar disso, (re)significaram suas identidades a partir de uma nova visão de mundo proporcionada pelo contato com e leitura literária (VALARINI, 2009).

Silva Neto (2009), a partir de uma pesquisa qualitativa, analisa as práticas e representações de leitura dos detentos alfabetizadores e alfabetizados do Complexo Prisional de Aparecida de Goiânia. A pesquisa tem como objetivo analisar o discurso dos detentos que participaram de um processo de alfabetização dentro do Complexo Prisional, na tentativa de compreender as suas práticas e representações de leitura, a partir do próprio discurso dos pesquisados.

O trabalho evidenciou que as precárias condições do presídio interferem no processo de ensino e aprendizagem. Nesse sentido, a pesquisa ressalta a necessidade do incentivo às práticas de leitura em ambientes adequados, formais ou informais, como componente de uma política pública de Educação de Jovens e Adultos dentro dos espaços prisionais. São necessárias a "implantação de políticas públicas voltadas para o incentivo da leitura e de práticas educativas que valorizam o leitor preso nos espaços de privação da liberdade" (SILVA NETO, 2009, p. 27).

Esse trabalho vai ao encontro com o que postula Ribeiro (2012, p. 130). O autor aponta para a necessidade de políticas públicas de incentivo à leitura como mecanismo de auxílio no resgate da identidade e da (re)socialização de sujeitos. "A inexistência de políticas públicas de incentivo à leitura e a ausência de padronização dos serviços oferecidos nas instituições penais comprometem a formação do leitor e a propagação da leitura como ferramenta de auxílio na reinserção do preso à sociedade".

Ribeiro (2012) investiga o perfil do leitor em situação de privação de liberdade e, além disso, discute a compreensão do processo moderno de encarceramento, considerando o efeito da prisionização no comportamento do leitor inserido nessa sociedade marginal. A pesquisa para resultados que confirmam a existência de comunidades leitoras no sistema prisional do Distrito Federal e evidenciam dificuldades próprias do ambiente carcerário para a apropriação da leitura.

Convém destacar o trabalho de Gusmão (2012), que apresenta um estudo sobre as práticas de leitura e a constituição da identidade leitora de apenadas do Complexo Penitenciário Feminino Estêvão Pinto, localizado na cidade de Belo Horizonte - MG. O objetivo do trabalho foi reconstituir, por meio de relatos de leituras das presas, a formação de suas 
identidades leitoras, localizando também os espaços de leitura, os modos de ler, os objetos de leitura e sua importância no mundo carcerário.

A leitura dentro da penitenciária "segue um padrão rígido imposto pelas condições de vida das presas, mas a normalização imposta a essa leitura não tira da cena a leitura como um acontecimento na vida das detentas" (GUSMÃO, 2012, p. 90). Além disso, a autora conclui que leitura tem suas condições para acontecer no ambiente penitenciário. A leitura, nesse cenário, é uma prática geralmente individual, uma vez que sujeitos apenados leem dentro de uma cela e em horário específico, entretanto, isso não impede que as detentas deixem de ler ou de atribuírem um sentido a aquilo que leem.

Já Magalhães Neto (2013) analisa eventos de letramento ocorridos no interior da Penitenciária Colônia Agrícola Major César Oliveira, Altos - PI. A pesquisa tem como objetivo central identificar, descrever e analisar os eventos de letramentos em situação carcerária, para verificar a dinâmica das práticas sociais de letramento nesse contexto, por textos orais e escritos, produzidos por apenados dessa instituição. Vale lembrar que a produção de textos orais e escritos possui uma relação direta com as práticas de leitura (PARANÁ, 2009).

A pesquisa etnográfica, exploratória, de cunho qualitativo, descritivo (MAGALHÃES NETO, 2013) revela que as condições de letramento a que se expõem rotineiramente aos sujeitos desta pesquisa são eficientes, pois as interações presentes no sistema carcerário são marcadas por práticas sociais que proporcionam aos sujeitos os usos da leitura, da fala e da escrita, por meio de ações educativas e cotidianas, como, por exemplo, a participação em feiras e cultos religiosos.

No que se refere à remição de pena pela leitura, Proença (2015) desenvolve uma pesquisa de caráter bibliográfico e exploratório, tendo como enfoque o letramento literário no Projeto Remição pela leitura em duas unidades penais do estado do Paraná: a Penitenciária Estadual de Londrina I e Centro de Ressocialização de Londrina.

O projeto "oportuniza não apenas o conhecimento, a cultura, a informação, mas do ponto de vista da educação, possibilita práticas de letramentos por meio da leitura literária, agregando a produção textual às práticas sociais da leitura e da escrita" (PROENÇA, 2015, p. 126). Nessa conjuntura, a autora destaca a importância de serem adotadas práticas pedagógicas que tenham como principal fundamento um trabalho mais flexível com as práticas sociais da leitura e da escrita nesses contextos. 
Apesar de termos diversos trabalhos e programas que vão ao encontro da leitura na penitenciária, ainda não é possível ter clareza da efetivação de políticas neste cenário, tendo em vista que

\begin{abstract}
Infelizmente, a ausência de uma cultura de acompanhamento e avaliação de políticas públicas no Brasil não tem possibilitado verificar se há resultados concretos em relação às ações previstas e realizadas nesta direção. As informações são imprecisas e não fundamentadas, impossibilitando avaliações mais objetivas sobre o tema (JULIÃO; PAIVA, 2014, p.117).
\end{abstract}

Nesse aspecto é que pesquisas, em torno da temática, vêm recebendo enfoque nos últimos anos, tendo em vista a necessidade de identificar a real implementação de políticas no âmbito da penitenciária e sua funcionalidade, articulando teoria e prática de forma a contribuir com o processo de humanização, que deve(ria) ser inerente a este contexto, entretanto, este fato ainda é considerado utopia.

Políticas de leitura no sistema penitenciário: um olhar para a lei de remição de pena pela leitura $n^{\circ}$. 17.329/2012

A lei de remição de pena pelo estudo foi aprovada a partir de uma série de trabalhos desenvolvidos por instituições governamentais e não-governamentais. Destacamos o Relatório Nacional para o Direito Humano à Educação nas Prisões Brasileiras (BRASIL, 2009) que, diante do quadro vivenciado no cenário nacional, apresenta uma série de recomendações a serem implantadas no sistema carcerário brasileiro e, entre elas, destacamos: aprovação da lei da remição da pena por estudo e uma política de estímulo à leitura e à escrita nas unidades prisionais.

Em consonância com as recomendações, nos anos seguintes destacamos a Lei no. 12.433 de 29 de junho de 2011, que altera a Lei n. 7.210, de 11 de julho de 1984 - Lei de Execução Penal - para dispor sobre a remição de parte do tempo de execução da pena por estudo ou por trabalho. Ao tratar da remição de pena pelo estudo, permite ao apenado remir um dia de pena a cada 12 horas de estudo, por meio de atividade de ensino fundamental, médio, profissionalizante, ou superior, ou ainda de requalificação profissional que podem ser divididos em três dias de aulas (BRASIL, 2011). 
Além disso, o Relatório Nacional para o Direito Humano à Educação nas Prisões Brasileiras (BRASIL, 2009) propunha a criação de uma política de estímulo à leitura e à escrita nas unidades prisionais. De acordo com o documento, o Ministério da Educação estabeleceu, no início de 2009, convênios por meio de Planos de Ações Articuladas com 19 estados para a implantação de bibliotecas nas unidades prisionais. O relatório destaca os convênios como um importante avanço que precisa ser complementado com a normatização nacional que estabeleça regras para a implantação, renovação de bibliotecas, composição do acervo, acesso dos encarcerados e das encarceradas, punição a gestores que mantiverem acervos fechados ou restringirem o acesso e regras para o caso de extravio de livro, estabelecendo diferenciação com relação às punições disciplinares da prisão. Nessa conjuntura,

Especial atenção deve ser dada a projetos e programas de estímulo e mediação de leitura nas unidades, com ou sem participação de organizações da sociedade civil. Existem experiências importantes que devem ser analisadas e divulgadas como referência para todo o sistema prisional (BRASIL, 2009, p. 95).

Em conformidade com o relatório, a Portaria Conjunta no. 276, de 20 de junho de $2012^{7}$, instituída pelo departamento penitenciário nacional (DEPEN), disciplina o projeto de remição pela leitura no âmbito das penitenciárias federais. De acordo com o art. $3^{\circ}$, a participação do preso "dar-se-á de forma voluntária, sendo disponibilizado ao participante 01 (um) exemplar de obra literária, clássica, científica ou filosófica, dentre outras, de acordo com as obras disponíveis na Unidade", podendo remir até quatro dias no mês, a partir da elaboração de resenhas e relatórios de leitura.

A partir da Portaria n. 276/2012, o estado do Paraná é pioneiro no que se refere à efetivação da remição pela leitura, uma vez que o documento é base para a criação da lei paranaense no 17.329 de 08 de outubro de 2012, que em ser art. $1^{\circ}$ institui o Projeto "Remição pela Leitura" nos Estabelecimentos Penais do Estado do Paraná como meio de viabilizar a remição da pena por estudo, prevista na Lei Federal no. 12.433, de 29 de junho de 2011 (PARANÁ, 2012).

Em seu art. 2०, O Projeto "Remição pela Leitura" tem como objetivo oportunizar aos presos alfabetizados o direito ao conhecimento,

7 Disponível em: http://www.stj.jus.br/internet_docs/biblioteca/clippinglegislacao/POC_276 _2012_DPE.pdf Acesso em 05 de fevereiro de 2016, às 15h45 min.

Revista Educação e Emancipação, São Luís, v. 10, n. 2, maio/ago. 2017 
à educação, à cultura e ao desenvolvimento da capacidade crítica, por meio da leitura e da produção de relatórios de leituras e resenhas. Além disso, é evidente no art. 3०, o objetivo do projeto em oportunizar ao preso remir parte da pena pela leitura mensal de uma obra literária, clássica, científica ou filosófica, livros didáticos, inclusive livros didáticos da área de saúde, dentre outras, previamente selecionadas pela Comissão de Remição pela Leitura e pela elaboração de relatório de leitura ou resenha, nos termos desta Lei (PARANÁ, 2012).

A partir da lei de remição pela leitura, o preso custodiado poderá remir até quatro dias de sua pena a cada trinta dias, a partir da leitura de obras e da escrita individual de resenhas ou relatórios de leitura. A lei determina, ainda, que uma comissão de Remição pela Leitura seja criada e constituída por profissionais da educação nos Estabelecimentos Penais, composta por um professor de Língua Portuguesa e um pedagogo, disponibilizados ao Centro de Educação Básica para Jovens e Adultos, instituição responsável pela educação em Estabelecimento Penal (PARANÁ, 2012).

Nessa conjuntura, vale destacar as palavras de Cândido (1995) quando menciona a literatura como "fator indispensável de humanização". Para o autor, a literatura confirma o homem na sua humanidade, uma vez que atua em seu inconsciente e subconsciente. Nesse sentido, ela pode agir em prol da educação familiar, social ou grupal. Assim, vale destacar ainda que

[...] nas nossas sociedades a literatura tem sido um instrumento poderoso de instrução e educação, entrando nos currículos, sendo proposta a cada um como equipamento intelectual e afetivo. Os valores que a sociedade preconiza, ou que os considera prejudiciais, estão presentes nas diversas manifestações da ficção, da poesia e da ação dramática. A literatura confirma e nega, propõe e denuncia, apoia e combate, fornecendo a possibilidade de vivermos dialeticamente os problemas (CÂNDIDO, 1995, p. 175).

A partir disso, notamos o poder da leitura literária em ambientes de privação de liberdade. Ao considerarmos a penitenciária como um espaço (re)socialização, entendemos a forte contribuição que a leitura pode nos oferecer nesses espaços, uma vez que a literatura traz conceitos e temáticas que se aproximam de cada leitor, produz e (re)produz sentidos e a cada leitura forma um novo leitor. Isso é possível porque 
a literatura é uma forma de expressão e conhecimento, que manifesta emoções, visões de mundo de indivíduos e de grupos.

Assim, a oferta de educação em ambientes de privação de liberdade, a partir das "Diretrizes Nacionais para a oferta de educação para jovens e adultos em situação de privação de liberdade nos estabelecimentos penais", em seu Art. $3^{\circ}$, inciso III, está associada

[...] às ações complementares de cultura, esporte, inclusão digital, educação profissional, fomento à leitura e a programas de implantação, recuperação e manutenção de bibliotecas destinadas ao atendimento à população privada de liberdade, inclusive as ações de valorização dos profissionais que trabaIham nesses espaços (BRASIL, 2010, grifo nosso).

Isso demonstra que, mesmo a passos lentos, a educação começa a ser preocupação em ambientes de ressocialização. No âmbito das práticas de leitura, ao pensarmos o leitor enquanto aquele que atribui sentido à leitura, não podemos deixar de lado os múltiplos efeitos de sentido que podem ser instaurados a partir de um texto literário ou não, uma vez que cada sujeito traz consigo uma bagagem cultural e ideológica diferenciada. Além disso, há leitores que possuem um conhecimento de mundo maior em relação a outros, sendo um forte aliado no momento da interpretação. Não se pode perder de vista que, nesse processo, ocorre um grande jogo de força ideológico, determinante de certas leituras que se dá, tanto por meio do texto, quanto por meio do leitor.

Como se observa, o exposto vai ao encontro do que cita Leffa (1996), quando postula que o processo de leitura envolve diversos aspectos, atendendo não apenas características do texto e do momento histórico em que ele é produzido, mas também características do leitor e do momento histórico em que o texto é lido, neste caso, um contexto que envolve leitores que não interagem com um mundo exterior ao da prisão.

Para as Diretrizes Curriculares Estaduais de Língua Portuguesa, a literatura, como produção humana, está intrinsecamente ligada à vida social. "A função social, por sua vez, é a forma como a literatura retrata os diversos segmentos da sociedade, é a representação social e humana" (PARANÁ, 2009, p. 58). Assim,

[...] a leitura é vista como um ato dialógico, interlocutivo. O leitor, nesse contexto, tem um papel ativo no 
processo da leitura, e para se efetivar como coprodutor, procura pistas formais, formula e reformula hipóteses, aceita ou rejeita conclusões, usa estratégias baseadas no seu conhecimento linguístico, nas suas experiências e na sua vivência sociocultural (PARANÁ, 2009, p. 71).

Nesse âmbito, a leitura por essa perspectiva (PARANÁ, 2009) propicia o desenvolvimento de uma atitude crítica que leva o aluno a perceber o sujeito presente nos textos e, ainda, tomar uma atitude responsiva ${ }^{8}$ diante deles. Acreditamos que assim, serão desenvolvidos "conhecimentos, compreensão, atitudes sociais e comportamento, que perdurem além da prisão e permitam ao apenado o acesso ao emprego ou a uma capacitação superior, que, sobretudo, propicie mudanças de valores, pautando-se em princípios éticos e morais" (BRASIL, 2013, p. 319).

Por esse viés, ao olharmos para a leitura enquanto uma experiência, sabemos que o texto age sobre o leitor, podendo exercer uma influência concreta, sendo aquela que confirma ou modifica as atitudes e práticas imediatas do leitor e as que se concentram em recrear e divertir. Vale lembrar que alguns textos, por trás de desafios de prazer explícitos (cômico, distração, emoção), escondem-se verdadeiros desafios performativos que informam, convencem e argumentam (JOUVE, 2002).

\section{Considerações finais}

A partir das discussões elencadas neste artigo, demarcamos alguns dos trabalhos desenvolvidos no âmbito do ensino da leitura no sistema prisional. É possível notarmos a seriedade das pesquisas e a importância de lançarmos um olhar para sujeitos e espaços marginalizados pela sociedade. O papel da leitura literária, nesses ambientes, vai ao encontro de o que postula Cândido (1989), posto que a literatura é um direito humanizador, uma vez que desenvolve nos sujeitos a quota de humanidade na medida em que os torna mais compreensivos e abertos para a natureza da sociedade, além de propiciar eventos de letramento significantes.

Uma das possíveis lacunas, nesse caso, seria a falta de trabalhos que discutem, especificadamente, políticas de leitura. As problemáticas

8 Termo bakhtiniano que permeia as Diretrizes Curriculares Estaduais de Língua Portuguesa. Implica em uma ação concreta dotada de intencionalidade praticada por alguém (BAKHTIN, 1992). 
que envolvem o ensino de leitura no sistema penitenciário são recorrentes e, mesmo sabendo dos benefícios que a leitura proporciona são inúmeros (BRITO, 2010), ainda faltam diversos direcionamentos que se pautem na efetivação de práticas de leitura significativas. Essa situação pode ser agravada, sobretudo, pela pseudoefetivação de políticas que regem esses contextos.

A leitura não se resume a decifração de códigos (CÂNDIDO, 1995); (JOUVE, 2002); (LEFFA, 1996); (SILVA, 2005); (PARANÁ, 2009), mas envolve um contexto mais amplo que considera o mundo e os sujeitos que dele fazem parte. O diálogo, nesse contexto, é pressuposto para ler e pronunciar o mundo, tendo em vista que "[...] é uma exigência existencial". É dizendo a palavra e pronunciando o mundo que "os homens o transformam, o diálogo se impõe como caminho pelo qual os homens ganham significação enquanto homens" (FREIRE, 2005, p. 91).

A mediação das práticas educativas e de leitura ocorre por meio do diálogo, uma vez que "existir, humanamente, é pronunciar o mundo, é modifica-lo" (FREIRE, 2005, p. 90). O diálogo se impõe como caminho que leva os homens a sua significação enquanto homens. As práticas de leitura, sobretudo, aquelas mediadas pelo diálogo, buscam estratégias que ultrapassem práticas de educação bancária, na qual "o educador é o que diz a palavra; os educandos, os que a escutam docilmente" (FREIRE, 2005, p. 68).

No que se refere à lei de remição pela leitura, trata-se de uma iniciativa pertinente no processo de (re)socialização, tendo em vista seu caráter legal e humanizador. Entretanto, sua aplicabilidade, seus resultados e benefícios aos sujeitos privados de liberdade, só poderão ser avaliados a partir de estudos que tenham como enfoque este cenário. Além disso, é necessário, também, a incorporação de uma cultura de acompanhamento de projetos como este, para que a leitura, realmente, ultrapasse os muros da penitenciária.

\section{Referências}

BAKHTIN, Mikhail. Estética da Criação Verbal. São Paulo: Martins Fontes, 1992.

BARROS, Ana Maria; JORDÃO, Maria Perpétua Dantas. A cidadania e o sistema penitenciário brasileiro. v. 10, p. 1-15, Fustributário, Fortaleza, 2011. 
BRASIL. Relatoria Nacional para o Direito Humano à Educação: Educação nas Prisões Brasileiras / Denise Carreira e Suelaine Carneiro São Paulo: Plataforma DHESCA Brasil, 2009.

Resolução n 2, de 19 de maio de 2010. Dispõe sobre as Diretrizes Nacionais para a oferta de educação para jovens e adultos em situação de privação de liberdade nos estabelecimentos penais. Disponível em: http://portal.mec.gov.br/index.php?option=com_ docman\&view=download\&alias=5142-rceb002-10\&category_slug=maio2010-pdf\&ltemid=30192 Acesso em 13 de junho de 2016, às 23h.

.Lei 12.433 de 29 de junho de 2011. Altera a Lei $n$ - -7.210 , de 11 de julho de 1984 (Lei de Execução Penal), para dispor sobre a remição de parte do tempo de execução da pena por estudo ou por trabalho. Disponível em: http://www.planalto.gov.br/ccivil_03/_ ato2011-2014/2011/lei/l12433.htm Acesso em 09 de fevereiro de 2016, às $17 \mathrm{~h}$.

Portaria conjunta no. 276, de 20 de junho de 2012. Disciplina o projeto de remição pela leitura no Sistema Penitenciário Federal. Disponível em:http://www.stj.jus.br/internet_docs/biblioteca/ clippinglegislacao/POC_276_2012_DPE.pdf Acesso em 09 de fevereiro de 2016, às 17h50min.

.Diretrizes Nacionais para a oferta de educação para jovens e adultos em situação de privação de liberdade nos estabelecimentos penais. In: Diretrizes Curriculares Nacionais Gerais da Educação Básica / Ministério da Educação. Secretaria de Educação Básica. Diretoria de Currículos e Educação Integral, Brasília, 2013.

BRITO, Danielle Santos. A importância da leitura na formação social do indivíduo. Periódico de Divulgação Científica da FALS. ano 4 - n. 8, jun. 2010.

CANDIDO, A. Direitos Humanos e Literatura. In:Fester, A. C. Ribeiro (Org.) Direitos Humanos e Literatura. São Paulo: Brasiliense, 1989.

CÂNDIDO, Antônio. Vários Escritos. 3ª Ed. São Paulo: Duas Cidades, 1995.

CRUZ, Odete Ferreira da. Escrita: resgate da identidade de indivíduos em situações de reclusão - as oficinas de produção de texto da PEM. / Odete Ferreira da Cruz. - Maringá-PR: [s.n.], 2008. Dissertação (Mestrado em 
Letras). Universidade Estadual de Maringá. Programa de Pós-Graduação em Letras, 2008.

FERNANDES, Camila de Souza. Literatura e identidade: a recepção do texto literário na Penitenciária Estadual de Maringá. / Camila de Souza Fernandes. - Maringá, 2009. 115f. Dissertação (Mestrado em Letras) Universidade Estadual de Maringá, Departamento de Letras, Programa de Pós-Graduação em Letras, 2009.

FREIRE. Paulo. Pedagogia do Oprimido. 43a Ed. Rio de Janeiro: Paz e Terra, 2005.

GUSMÃO, Zilma da Silva. Histórias de mulheres detentas: um estudo sobre a construção da identidade leitora. 2012. 121f. Dissertação (Mestrado) - Pontifícia Universidade Católica de Minas Gerais. Programa de Pós-Graduação em Letras, Belo Horizonte, 2012.

JOUVE, Vicent. A leitura. Tradução de Brigitte Hervor. São Paulo: Unesp, 2002.

JULIÃO, Elionaldo Fernandes; PAIVA, Jane. A leitura no espaço carcerário. Perspectiva, Florianópolis, v. 32, n. 1, 111-128, jan./abr. 2014.

LEFFA, Vilson Jose. Fatores da compreensão na leitura. Cadernos do IL. Porto Alegre, v.15, n.15, 1996.

MAGALHÃES NETO, Pedro Rodrigues. Eventos de letramento em situação carcerária. 2013. 218f. Tese (Doutorado em Letras) - Doutorado interinstitucional, UFPE/IFPI/UESPI, Recife, 2013.

MARTHA, Alice Áurea Penteado. Leitores no presídio: histórias em construção. In: Vera Teixeira de Aguiar, Alice Áurea Penteado Martha (Orgs.). Território da leitura: da literatura aos leitores. São Paulo: Cultura Acadêmica; Assis, SP: ANEP, 2006.

OLIVEIRA, Daniela Carla de. O leitor e a leitura do texto literário na penitenciária estadual de Maringá, Paraná. 2004. Dissertação (Mestrado em Letras) - Programa de Pós-graduação em Letras. Universidade Estadual de Maringá, Maringá, 2004.

OLIVEIRA, Ivan Luiz de. A liberdade vigiada: estudos sobre os modos de recepção da obra o Alquimista, de Paulo Coelho, pelos detentos da Penitenciária Estadual de Maringá. 2007. Dissertação (Mestrado em Letras) - Universidade Estadual de Maringá, Maringá, 2007. 
PARANÁ, SEED. Diretrizes Curriculares da Rede de Educação Básica do Estado do Paraná (DCE). Língua Portuguesa. Curitiba: Secretaria de Estado da Educação, Superintendência da Educação, 2009.

.Lei no. 17.329, de oito de outubro de 2012. Institui o projeto "Remição pela Leitura" no âmbito dos estabelecimentos penais do estado do Paraná. Diário Oficial do Estado do Paraná. Ed. 8814, p. 10, 08 de outubro de 2012.

PROENÇA, Débora Maria. Remição pela leitura: o letramento literário ressignificando a educação na prisão. 2015. 157f. Dissertação (Mestrado) - Universidade Tecnológica Federal do Paraná. Programa de Mestrado em Ensino de Ciências Humanas, Sociais e da Natureza. Londrina, 2015.

RIBEIRO, Maria Luzineide P. da costa. 0 mundo como prisão e a prisão no mundo: Graciliano Ramos e a formação do leitor em presídios do Distrito Federal. 2012. 160f. Dissertação (Mestrado em Literatura) - Instituto de Letras, Departamento de teoria literária e literaturas, Universidade de Brasília, Brasília, 2012.

SILVA NETO, Antônio Artequilino. As práticas e representações de leitura dos detentos alfabetizadores e alfabetizados do Complexo Prisional de Aparecida de Goiânia. 2009. 187 f. Dissertação (Mestrado em Educação) - Faculdade de Educação, Universidade Federal de Goiás, Goiânia, 2009.

VALARINI, Sharlene Davantel. Diários de bordo: uma viagem pela leitura de textos com o tema infância na Penitenciária Estadual de Maringá. 2009, 222 f. Dissertação (Mestrado em Letras) - Universidade Estadual de Maringá, Maringá 2009.

Recebido em março/2017

Aceito em abril/2017 